\title{
A Guide to Student-active Online Learning in Engineering
}

\author{
Erik Kyrkjebø
}

Department of Computer Science, Electrical Engineering and Mathematics, Faculty of Engineering and Science, Western Norway University of Applied Sciences, Sogndal, Norway. E-mail: erik.kyrkjebo at hvl.no

\begin{abstract}
Online learning in higher education is becoming increasingly common as the possibilities of the available digital infrastructure expand. A recent emergent driver for online learning is the closing of universities to limit the spread of the coronavirus (COVID-19). Many educators are now faced with the need to make their teaching digital, though they have little or no experience with online teaching methods. In such a situation, learning outcomes may come second to what can be readily implemented by available digital resources. In this paper, a design for student-active online learning in engineering is proposed as a guide to help take account of learning objectives first, and the digital tools and resources necessary to achieve those objectives second. In addition, the paper emphasises the social dimension of online learning, and recommends that explicit actions should be taken to increase positive social relations between students in an online course to be able to succeed with student-active learning methods. In the paper, a clear path is followed from objectives to learning activities, and then to assessments and evaluations, and appropriate digital tools and resources are suggested to support activities and evaluations in an online course. Online courses in engineering are targeted in particular, and challenges that arise from common activities such as problem solving and practical work in an online engineering course are addressed. The proposed guide emphasises usability to ensure that it can be used even by inexperienced digital educators, and an example on how the guide can be applied to design an online course in mobile robotics is given. The proposed guide aims to help shift online learning in engineering from traditionally teacher-active lectures to more student-active learning activities.
\end{abstract}

Keywords: Online learning, Engineering, Social processes, Student-active, Mobile Robotics

\section{Introduction}

Many institutions in higher education worldwide are transforming their classes into online courses. This transformation is partly due to their need to be competitive as educational institutions, but also to make classes more accessible to a growing and more diverse group of students (Keengwe and Kidd, 2010). A recent emergent driver for online learning is the closing of universities to limit the spread of the coronavirus (COVID-19). Online teaching is often seen as more effective in teaching large student groups and to of- fer new possibilities in terms of digital pedagogy, and some studies also report that students prefer online courses to traditional classroom learning (Hannay and Newvine, 2006). Still, it is important to ensure that the course's learning objectives are not sacrificed on the altar of digital enthusiasm, and that we consider learning objectives and activities first, and then the digital tools and resources that can help us implement those activities second.

The learning retention of different learning strategies have been studied extensively for the last 80 years. The 
popular learning pyramid ${ }^{1}$ (origin unknown) is familiar to many educators in higher education, and illustrates the retention rates of different learning strategies ranging from lecturing (5\%), reading (10\%), audiovisual (20\%), demonstration (30\%), group discussion (50\%), practising $(75 \%)$, and teaching others/using immediately $(90 \%)$. The first version of the pyramid is often wrongly attributed to the text Audio-visual Methods in Teaching by Edgar Dale in 1954 (Dale, 1954), but many versions of the pyramid exist - often with different percentages for the different levels. In Letrud (2012) and Lalley and Miller (2007), systematic rebuttals of the learning pyramid are presented, questioning the origin and research behind the model, and the methodology that had to be used to derive such a model. Furthermore, the NTL Institute in the US, one of the pyramid's most active proponents, even claims that the original data supporting the learning pyramid have been lost.

In Lalley and Miller (2007), the learning pyramid's origin is instead suggested to be a synthesis of two separate sources. One is from the works of E. Dale and his "cone of experience" from 1949 (in the first edition of the text in Dale (1954)) as a model of learning experience (without percentages), and the other source is an old retention chart with rates associated with reading, seeing, hearing, and doing originating from before 1940. Note that the cone of experience from Dale is referred to as a continuum of methods in Lalley and Miller (2007) rather than as a hierarchy. According to Lalley and Miller (2007), no credible research could be found to support the learning pyramid itself, but research supporting the importance of each of the methods in the different pyramid levels was found - although no method consistently performed better than the others in different contexts. The conclusion of Lalley and Miller (2007) was rather on the importance of the teacher as a knowledgeable decision maker in choosing appropriate teaching methods.

Student-active learning, with more engagement from students in the learning process, has been shown to be beneficial for learning, despite the lack of evidence supporting the learning pyramid itself. A meta analysis of 225 studies of examination scores or fail rates, using active learning compared with traditional lecturing reported in Freeman et al. (2014), found that average examination scores increased by about $6 \%$, and fail rates decreased by $55 \%$. Students in classes with traditional lecturing were 1.5 times more likely to fail than were students in classes with active learning. The results were found to hold across undergraduate STEM (science, technology, engineering, and mathematics) disciplines and to be robust to variations in active learning

\footnotetext{
$1_{\text {https://tinyurl.com/ntl-learningpyramid }}$
}

methods, but to increase scores more on active concept inventories than on course examinations. Active learning was also found to be effective for all class sizes studied, but to be more effective in small $(n \leq 50)$ classes. However, Freeman et al. (2014) also notes that all studies included teachers who volunteered to use active learning methods, and that effect sizes could be less if active learning approaches were mandatory for all teaching activities and teachers. Wieman (2014) commented on the findings of Freeman et al. (2014) to claim that it is becoming increasingly clear that "active learning methods achieve better educational outcomes". Wieman also suggests that good active learning tasks simulate real-life problem solving, and thus require more subject expertise from the teacher than lecturing does. This relationship between required expertise and active learning methods could explain some of the effects of active learning on learning outcomes across different STEM disciplines and levels of courses.

Biggs (1999) looks at how active learning is likely to stimulate more high-level cognitive engagement from students - both for more academically oriented students and for less self-motivated non-academically oriented students. Biggs postulates that "Good teaching is about making most students use the higher cognitive level $[$ sic] processes that the more academic students use spontaneously" (Biggs, 1999). While academic students are likely to adopt a deep-level approach to learning (learning the intentional content (Marton and Säljö, 1976)), the less academic students are likely to use a surface-level approach to learning (with a reproductive aim (Marton and Säljö, 1976)), unless the most favourable learning conditions are met - which is active learning, according to Biggs (1999). Biggs also postulates that education is about a conceptual change in the students' understanding, not just acquisition of information, and therefore that the meaning of a concept cannot be imposed or transmitted through direct instruction, but instead must be created through students' learning activities. Conceptual change may take place when students work towards appropriate and well-known goals (objectives), feel the need to get to the goal, feel free to focus on their task and not watch their backs, and can work collaboratively with each other (and the teacher). To structure the process of conceptual changes in students, Biggs (1999) introduced the concept of "constructive alignment", where the desired outcomes of the course directly specify the learning objectives. These objectives in turn define what we should be teaching, how we should be teaching it, and how we can evaluate how well students have learned it. A major point of Biggs (1999) is that the learning activities and assessments should be designed to align with the objectives of the course, and that ac- 
tivities should encourage students to engage more in higher-level cognitive engagements, such as theorising, applying, relating, and explaining, than in describing, note-taking, or memorising.

The view that students should work collaboratively with others, expressed in Biggs (1999), is very much aligned with the views later presented by Johnson and Johnson (2009), advocating the use of cooperative learning over individualistic or competitive learning based on social interdependence theory. "Social interdependence exists when the outcomes of individuals are affected by their own and others' actions" (Johnson and Johnson, 2009). One of the major findings of Johnson and Johnson (2009) is that groups perform better if they have a positive interdependence - especially if there is a positive goal (and reward) interdependence. Since the interdependence can be defined along several axes such as common goals, common outcomes, interpersonal bonds, and communication, there is evidence that groups also developing their social interrelations positively while working towards goals perform better. Another finding of Johnson and Johnson (2009) was that individual accountability within the group (where the performance of each individual member is assessed) leads to higher achievements, and that members of a group might reduce their contributions if individual contributions are difficult to identify. Group size also affects individual accountability, which typically diminishes as groups grow large (Johnson and Johnson, 2009).

Online learning has been a topic of increasing interest over the past two decades. Goodyear (2002) defines online learning to mean "learning which involves interaction between people using Internet communication technologies", and regards "e-learning" and "networked learning" as synonyms for online learning. Keengwe and Kidd (2010) also include "webbased training and instruction", "distributed learning", "cyber learning", and "virtual learning" in the group of synonyms, while other authors distinguish between these concepts.

Online learning may be divided into synchronous and asynchronous learning activities. Synchronous learning activities require participants (teacher and students, or students and other students) to be online simultaneously for real-time lecturing, supervision, demonstrations, discussions, or the like. Asynchronous activities are, according to Goodyear (2002), interactions where participants are allowed to take part in the interaction at different times, and encompass activities such as watching recorded lectures or doing online simulations individually. Text-based discussions can either be synchronous, where participants expect almost instant replies (chats), or asynchronous, where partici- pants can wait longer for more elaborate replies (forums, email).

Salmon (2002) introduced the "five-stage framework and e-tivities" for active online learning to motivate participants and to build learning through appropriate activities. At stage 1, access and motivation, students gain access and are welcomed. At stage 2, online socialisation, students are interacting and building relationships. At stage 3, information exchange, participants exchange information. At stage 4 , knowledge construction, the interaction is more collaborative. And at stage 5, development, students look for more benefits for them personally, and reflect on the learning process. The five-stage model of Salmon (2002) corresponds well with the cooperative learning approach with group processing described by Johnson and Johnson (2009), where group participants reflect and make decisions on which actions are helpful towards achieving the group goals, and which actions are not. The work of Salmon (2002) is also very well aligned with how the learning process should be designed to be more active, proposed by Wieman (2014), building on the results in Freeman et al. (2014).

Blended learning, or hybrid learning, is learning in which face-to-face learning is combined with online learning, and can often encourage surface-level students, who are less self-regulated, to stay focused on the course (Olapiriyakul and Scher, 2006). Another motivation for choosing a blended learning strategy is that students have reported feeling a greater sense of community in blended courses than in purely online courses. Studies presented in Olapiriyakul and Scher (2006) also suggest that a majority of hybrid learning projects show improvements in student learning. It is reported that student attendance in physical classroom sessions may go down in blended learning environments, and that the sense of community will help combat this effect. While Hannay and Newvine (2006) found that students preferred online learning mainly because of better being able to balance learning with other commitments - the authors also suggest that there may be educational advantages to integrating the best aspects of distance learning into traditional courses to build a hybrid learning environment.

Hampel (2006) looked at synchronous online teaching and how to adapt classroom teaching techniques to online teaching, and how to devise new teaching activities in an online environment. Hampel warns not to let all the new digital innovations in computer-mediated communications (CMC) "lead us to the conclusion that we can now replicate in $\mathrm{CMC}$ what we do in the faceto-face classroom". When teaching is done using online video systems, Hampel claims that the system can allow for immediate responses from participants and for 
more authentic dialog than in asynchronous modes of online learning (but perhaps with less reflection). But participants who are unfamiliar with the technology, or who are participating in a poorly moderated session, can feel more left out than in a real-life classroom. An important point of Hampel is also that students who are more familiar with hierarchical learning environments, where direct instructions or lecturing are dominant learning methods, need to be encouraged to use the more democratic and student-centred features that are available in many online learning environments. Studies summarised in Keengwe and Kidd (2010), on best practices in online learning, report that while traditional learning environments are bound by the location and presence of participants, presented in real time, often controlled by the teacher, and mostly linear in teaching methods - online learning environments can be more unbound and dynamic environments, and often employ a greater number of active learning techniques.

In this paper, a design for student-active online learning in engineering is proposed to help digital educators to formulate learning objectives before choosing the digital tools to aid in the learning activities. The paper adopts the structure of conceptual alignment of objectives, activities, and assessments from Biggs (1999) to propose a guide for choosing active learning activities and corresponding methods of evaluation and assessment based on the learning objectives. Digital tools that can support both the learning activities and the evaluation process are suggested. In addition to the dimensions of cognitive engagement and learning activities found in Biggs (1999), the paper also emphasise the social dimension of creating an online learning environment with positive social interdependence between students based on the findings of Johnson and Johnson (2009), and as a prerequisite for active learning to succeed, according to Salmon (2002). The proposed guide targets in particular active online learning of engineering skills - which often has a practical aspect of learning to work on physical infrastructure - to recognise that not all activities can necessarily be done online in this field, and therefore may need a blended learning approach. The paper is concluded with an example where the guide is applied to design an online course on mobile robotics for engineering students.

A more detailed background on active learning activities is presented in Section 2, before the particular aspects of active learning in engineering are commented on in Section 3. Section 4 proposes to view active online learning in three dimensions to make sure social objectives are included in the learning design, before a guide for active online learning of engineering is presented in Section 5. The guide is applied to design an online course in mobile robotics in Section 6, before conclusions are presented in Section 7.

\section{Active learning}

This section will elaborate on what the term active learning can encompass. Later sections will present what is considered to be particular challenges for designing student-active learning activities in online engineering courses.

In Freeman et al. (2014), active learning is defined as follows:

Active learning engages students in the process of learning through activities and/or discussion in class, as opposed to passively listening to an expert. It emphasises higher-order thinking and often involves group work.

Traditional lecturing is described as "continuous exposition by the teacher" where student activity is "assumed to be limited to taking notes and/or asking occasional and unprompted questions of the instructor" (Freeman et al., 2014). In Wieman (2014), the gist of active learning methods lies in requiring students to actively process and apply information in a variety of activities such as answering questions, completing exercises, or discussing in groups, and where the teacher's role is to design the activities and provide follow-up guidance. It is also suggested that good active learning tasks simulate real-life problem solving.

In Lalley and Miller (2007), finding little evidence to support the learning pyramid itself, the authors instead focused on what the available research on the methods identified in the learning pyramid could say about learning retention for each particular method. In doing so, Lalley and Miller (2007) found the following:

- Lecturing, or direct instruction, emphasises teacher direction to "assist student attainment of lesson objectives". It is the most researched teaching strategy, the strategy that has improved student performance the most, it has been shown to have a significant effect on retention, and it has been found useful for students across grades, and for students of low socioeconomic status (with typically less background knowledge). However, Bay et al. in Lalley and Miller (2007) claim that while direct instruction could be more successful "for basic skill instruction in reading and mathematics, such teaching may be less beneficial for science".

- Reading and understanding the text have significant impact on students' ability to remember what they have read, and there is a significant positive relation between the number of structured reading 
lessons and students' gains on reading comprehension tests.

- Audiovisual materials can hardly be precisely defined as a method, but can include pictures, graphs, sounds, videos, or other media. Few studies on audiovisual methods address retention, but some indicate that a visual experience can enhance learning in learning-disabled children. Computer simulations or virtual reality have promise to increase the possibility to practise new forms of discovery-learning techniques.

- Demonstration involves a teacher performing a learning task while students observe, to exemplify correct behaviour or use. Research on retention for this method is relatively sparse, but some results indicate that demonstrations lead to increased retention - and similar retention whether students took turns observing each other, or whether students themselves performed the demonstration following a teacher's demonstration. Similar retention rates could even be shown between hands-on learning in a laboratory and a lecture/demonstration combination (by Pigford (1974) in Lalley and Miller (2007)).

- Group discussions and cooperative learning have been investigated in many studies and meta analyses, and results indicate higher levels of student achievement when using cooperative (smallgroup) learning than when using competitive or individualistic approaches (Johnson and Johnson, 2009). Results showed that cooperative learning with group processing (reflection and discussing on member contributions at the end of a session) is more effective than only cooperative learning alone (and much more effective than individualistic approaches).

- Practise by doing can let students work (individually or in groups) to discover principles or relationships to develop a personally meaningful understanding of the concept (discovery learning), and studies have shown that students retained more information when concepts were introduced through a practical laboratory context followed by a lecture/reading than vice versa. Some studies have shown that discovery learning (environmental learning) can result in greater learning than is possible from direct instruction (presentational learning), but other studies have shown no difference in retention rates. Overall, it is still an open question if discovery learning gives better retention rates than does demonstration learning or direct instruction.
- Teaching others through peer tutoring has been shown to improve achievement, but then it often involves reciprocal tutoring by taking turns being the tutor, and there is little research on the effect of tutoring on the tutor rather than on the one being taught. Still, there are indications that being a tutor leads to better retention for the students who tutored than for the students who did not tutor.

The authors in Lalley and Miller (2007) were careful not to put the concepts above in a hierarchical structure, nor to associate any retention rates with the different concepts. The major conclusion was that all methods are dependent on the context, and that teachers should take care to choose the teaching strategy best suited to the subject, to the students' capabilities, and to the students' skills. Most importantly, and as suggested by Dale (1954), the most successful teaching strategy would likely involve a variety of teaching methods.

The body of research on learning as presented above suggests that student-active learning methods are better than teacher-active learning methods in many contexts, but also that lecturing is a valid and effective teaching method in some contexts. The most important teaching strategy is that which exposes students to a variety of learning methods best suited to the particular topic at hand. Next, the contexts engineering educators are faced with that should make us particularly interested in some of these student-active learning approaches are presented.

\section{Active learning of engineering}

What distinguishes teaching engineering from teaching other subjects? And what are the most important considerations that should be kept in mind when trying to teach engineering through active online learning? To answer these questions, we should try to find an answer to what engineering is, but it could be easier to say what engineering is not, according to Goodhew (2014). In his book, Goodhew claims that engineering education is not about teaching specific practical skills, or about running code or machines, or about signing off on blueprints or contracts. An engineering education is "about the conceptual, planning and design skills which should precede all these activities". In a report from the National Academy of Engineering (2008) (NAE), emphasis is put on how engineering affects the real world through problem solving, rather than on how engineering is a mathematical and science-based method of solving problems. Furthermore, the skills of creativity, teamwork, and communication are often neglected in characterising engineering, 
according to Goodhew (2014). In Pawley (2009), interviews with academic engineers concluded that three major concepts are closely attributed to the discipline of engineering: mathematics and applied science, problem solving, and making things. Furthermore, Pawley (2009) also refers to the NAE statements about engineering being "the application of science" and "design under constraints" to encompass that engineering does not take place in an ideal world, but must adhere to the constraints and disturbances of real life.

It is hard to find a definition of engineering that encompasses all aspects of the discipline, but there are some parts of the engineering education that should at least be considered when designing active online learning approaches to engineering:

- Theoretical work learning concepts and methods that form the basis of knowledge for all engineering students. This theoretical work includes the mathematical and scientific foundations of engineering.

- Practical work on exercises through calculations, on computers in simulations, in laboratories, or in real life through experiments.

- Creative work in solving real-life problems or proposing new designs within limitations and constraints.

- Teamwork through cooperation with other people and other competencies on projects.

- Communication of results, insights, and concepts to fellow students, examiners, and the general public.

This list is far from exhaustive, but rather is an illustration on the nature of work that students of engineering encounter during their studies. Examining the parts more in detail, and using the different methods of learning from Lalley and Miller (2007) in Section 2, it is clear that an engineering education could include activities such as reading, lecturing, demonstrations, and practising - but probably could also include using appropriate cooperative activities, such as group discussions and students teaching others, to promote both scientific and social skills when working in groups. In fact, because of the problem-solving nature of engineering while adhering to external constraints, more emphasis should probably be placed on creative activities through teamwork and practise, than on oneway lecturing on theoretical concepts that are more applicable for learning purely theoretical and abstract concepts.

\section{Active online learning}

"Online learning" is a term that encompasses a lot of different learning schemes, but with the commonality that the learning activities are done online over the internet.

\subsection{Three dimensions of learning}

In the works of Biggs (1999, Fig. 1), the levels of engagement of students are shown for both deep-learning students and surface-level students ranging from passive teaching methods (e.g., lectures) to the more active learning methods (e.g., problem-based learning) - and with both student groups benefiting from the more active learning approach. The active learning approach is also very much supported by the findings in Freeman et al. (2014) and by the recommendations in Wieman (2014), and by the literature review on components of the "learning pyramid" in Lalley and Miller (2007). In Biggs (1999), the social dimension of learning is also touched upon, where students who are free to focus on the task rather than watching their backs are more likely to experience a conceptual change of understanding, and where Biggs also recommend working together in groups. However, this dimension is treated more explicitly in Johnson and Johnson (2009), where the achievement of the individual is found to be better in groups where there is a strong positive social interdependence between members.

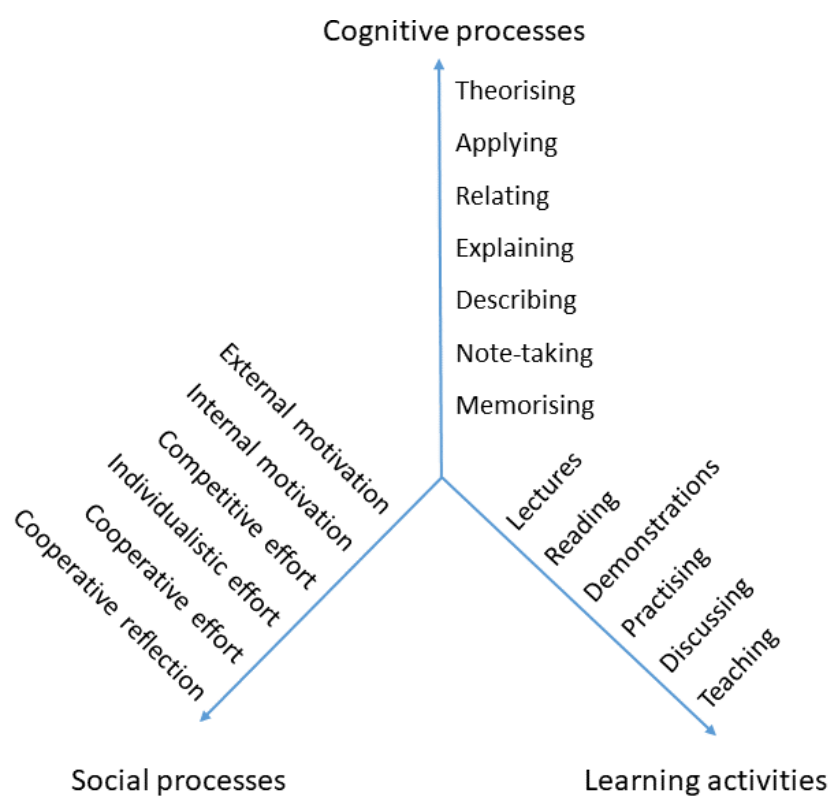

Figure 1: Three dimensions of learning

In this paper, I propose in Figure 1 to see the cognitive level of engagement, the passive/active learn- 
ing approach, and the social processes in the individual/group as three dimensions of an active learning environment that should explicitly be considered when designing an online active learning strategy. In the first dimension, the level of cognitive processes is inspired by Biggs (1999), who looked at how the more active learning methods stimulate higher cognitive-level processes in students. In the second dimension, some of the concepts from Dale (1954) and Lalley and Miller (2007) are adopted to describe different learning activities employed in teaching. Note that these methods are described from a student's viewpoint, and thus the descriptive term "lectures" is used to describe students attending lectures, while the active term "teaching" describes students engaged in teaching others. Note also that the category of audiovisual material from Lalley and Miller (2007) is omitted in this dimension, because this category is more of a tool than a teaching activity. The third dimension is the social processes of (online) learning, adopted from the results of Biggs (1999) and Marton and Säljö (1976) on deep learners (internally motivated) and surface learners (externally motivated), and from the works of Johnson and Johnson (2009) on social interdependence. This dimension is also supported by the five stages of online learning from Salmon (2002), where the activities of motivating and creating social relations are emphasised as important factors for successful online learning.

The three proposed dimensions of active learning should be taken as a guide for designing an active learning approach to online learning. In the cognitive dimension, it is natural to expect internally motivated students to employ almost all of these cognitive processes during a full course - or even during any given lecture. The externally motivated students, who employ a more surface-level learning approach, may be only memorising and note-taking. The point of Biggs (1999) is that it is more beneficial for achieving a conceptual change in understanding if students are more occupied with theorising and applying knowledge than with simply memorising or writing. Emphasis should therefore be on designing learning activities that stimulate the more high-level cognitive processes.

In the learning activity-dimension, no single learning strategy has been determined to work better than others in all contexts, according to Lalley and Miller (2007), and therefore the authors' suggestion is to use a variety of learning activities, and to use those best suited to the course material and the expected background knowledge level of the students. It is easy to imagine that an online course of only direct instruction through lectures could be quite monotonous to attend, and that even only a few demonstrations of concepts or a few experiments could break the monotony. Carefully choosing a variety of appropriate learning activities is therefore the main goal along this dimension.

The social dimension stipulates that the teacher must create a motivation for the learning process and some form of social relations between the students before group-based learning processes can be expected to work. In this dimension, the first goal is to move as many of the students from a surface-learning approach, with mainly external motivations from grades, job, paychecks, etc., to a deep-learning approach where students are to a larger extent motivated by internal factors. Note that Biggs (1999) proposes that this change can be achieved by employing more of the active learning strategies, which in turn engages the more high-level cognitive processes in students.

The available workspace of online learning methods available to the teacher is a tetrahedron formed by the level of cognitive processes, the learning activities, and the social processes of students as shown in Figure 2. The goal of active online learning is to make sure this workspace is at least as large as the objectives of the course dictate. If the learning objectives of the course expect students to explain or apply concepts, the learning activities should reflect these objectives to create a sufficiently large online learning workspace.

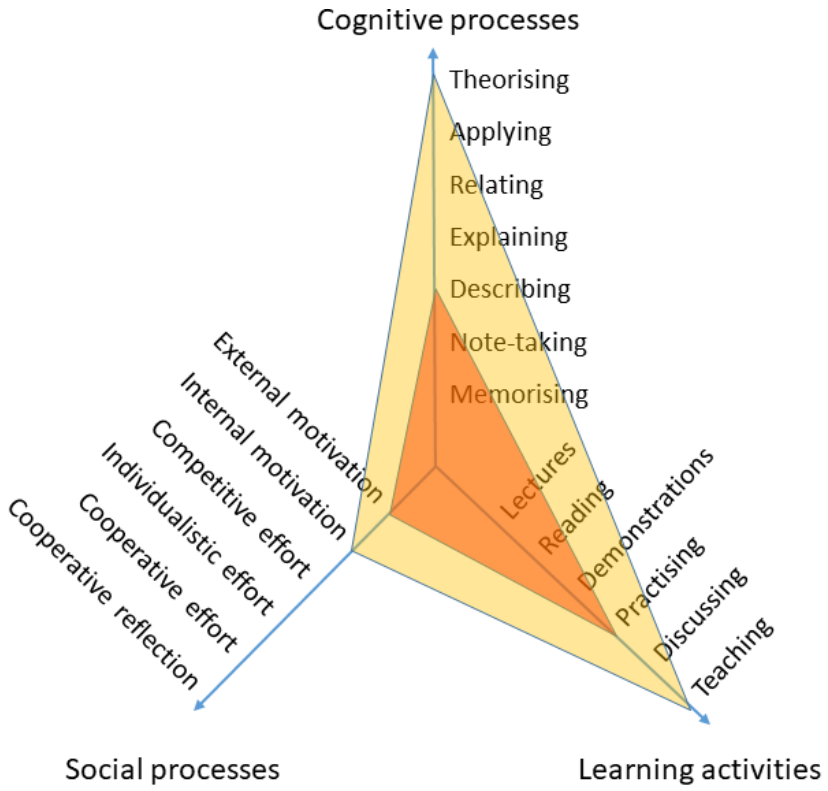

Figure 2: A surface approach to learning dominated by external motivating factors vs a deeper learning approach dominated by internal motivation factors.

Furthermore, based on the findings of Johnson and Johnson (2009), there is a hierarchy between a competitive learning effort, an individualistic learning effort, and a cooperative learning effort. The cooperative 
learning strategy has been shown to have better overall effects on achievements, but note that there are contexts where competitive and individualistic approaches may be warranted (lack of resources, high costs of cooperation, etc.). Note also that the cooperative learning approach with group processing of individuals' contributions to the cooperation - dubbed in this paper as "cooperative reflection" - has been found to show the highest effects on achievement. Competitive and individualistic efforts are supported by individualistic learning activities, while group-based learning activities support cooperative learning strategies, as illustrated in Figure 3. Note however, that there is not necessarily any difference between the level of cognitive processes that individuals engage in with these approaches - well-motivated students in an individualistic learning effort may also be theorising about the material. The point is rather that, according to Johnson and Johnson (2009), higher achievements can be accomplished through a cooperative learning effort if the context favours it.

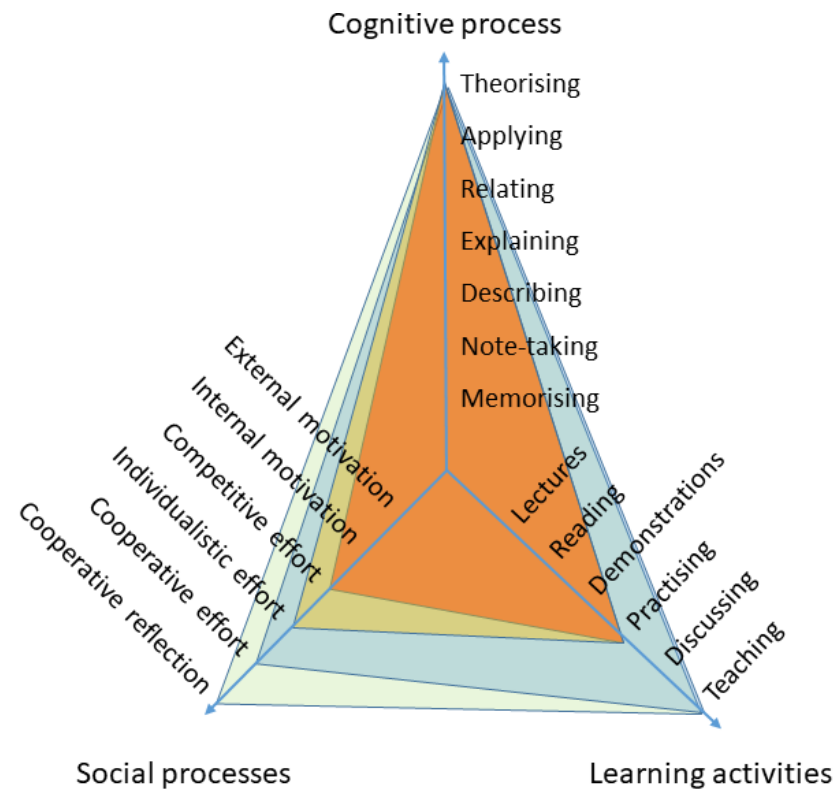

Figure 3: Competitive, individualistic, and cooperative learning efforts.

\subsection{Recommendations for learning in three dimensions}

What are the recommendations for active online learning that we can see from these proposed dimensions of learning? The first recommendation follows closely that of Biggs (1999) in that if teachers have a class of both deep learners and surface learners, employing the more active teaching strategies with clear and un- derstandable objectives for the learning activities will engage the more high-level cognitive process in students. The active learning strategies should, according to Biggs (1999), in turn lead to a conceptual change in students, and thus influence their motivation for learning to be more focused on the learning itself.

Wanting to employ the more active methods of teaching has a prerequisite of motivating students to participate in the learning activities, but also motivating them to create some form of positive social relations between each other. Again, one cannot expect group work to succeed if there is no effort to create some form of positive social relations between the group members. Competitive approaches to learning where students treat each other as competitors have been shown in Johnson and Johnson (2009) to be less effective than individualistic learning efforts, where the success of one individual does not come at a cost for others. Both individualistic and competitive approaches have been shown to be less effective than a cooperative learning strategy, where the success of the individual is also dependent on the success of others. The cooperative strategy also more readily incorporates learning activities such as discussions and teaching others. Thus, when designing learning activities, the teacher should consider whether the design encourages competition, individualistic work, or cooperation. From the findings in Johnson and Johnson (2009), online quizzes designed as competitions between individuals during lectures do not necessarily lead to lower scores, but online quizzes that group students together as teams, with enough time to create social relations and to reflect on the cooperation, are more likely to give higher scores over time.

The findings of Biggs (1999) and Johnson and Johnson (2009) suggest the conclusion that in addition to formulating clear academic objectives for the course and designing the learning activities and an assessment strategy to support those objectives, clear objectives on social interactions between students in the course should also be formulated if active learning is to be employed in the course. These social objectives are important for even the most basic active learning strategy of asking students a question while giving a lecture. If the social relations between students are not sufficiently supportive to encourage students to raise their hands, this learning strategy will fail to activate students.

The goal of active online learning should be to motivate students to employ high-level cognitive processes through using a variety of appropriate learning activities, and to create positive social relations between students through cooperative learning efforts where students and the teacher reflect on how the cooperation is 
working within the group.

\subsection{Synchronous, asynchronous, grouping, and blended learning}

Using the reflections in the preceding sections as a starting point, it is natural to suggest that to employ a variety of learning activities, not all activities should be asynchronous in online active learning. While reading is naturally asynchronous in nature, lectures with direct instruction and some forms of demonstrations lend themselves easily to asynchronous online video presentations - which can even include short quizzes on the lecture material embedded into the video stream. Discussing and teaching, however, will often benefit from a real-time interaction between participants. Written discussions through emails, discussion boards, and forums can to a certain extent make discussions and group activities an asynchronous activity, but for many contexts the easier (and sometimes more social) option could be to have online real-time discussions using some form of video conferencing systems or chats where all participants participate simultaneously.

An important point concerning online learning involving video is the perceived distance between the teacher and the students. On one hand, it is hard for the teacher to see all students simultaneously on video during synchronous activities with large groups, and of course there is even less feedback when students are working with asynchronous material. In addition, it is easy for students to become "watchers" rather than participants in both synchronous and asynchronous (video) activities. To combat students' feeling of passively watching a show rather than actively participating (engaging in higher-order cognitive processes), active learning is even more important in an online course than in a face-to-face course.

In the closing of schools and universities because of the coronavirus (COVID-19) in spring 2020, faculty and students were faced with transforming their learning activities to online learning in a very short period of time - with traditional physical classroom teaching no longer being an alternative. It is important to note that this transformation did not necessarily create an online course. When universities close, students are both forced to participate online, and forced to participate as individuals, because of the social distancing regulations. Courses are put online overnight, and very little planning for online learning can be expected.

Normal online learning situations include situations where parts of the campus course are taught online and parts are taught in physical classrooms (blended learning), or where parts of the student group are participating in the physical classroom while other parts are participating online, which we can call "blended group learning". In blended group learning, all students can participate on equal terms in asynchronous learning activities, but for synchronous activities, there are recognisable challenges in providing equal opportunities for learning for students and groups of students participating 1) face to face in the classroom with the teacher, 2) individually online, or 3) as members of groups online. Multi-campus universities giving the same course at different campuses may easily have a group participating face to face, other groups participating online, and also have individual students participating from home. It is important to address the different group dynamics that can occur during these different scenarios when designing courses for online learning.

Faced with the heterogeneous distribution of students in groups and individually, and between face-toface and online students, some of the major challenges are 1) to create positive social relations between individuals, 2) to decide whether face-to-face students and online students should be in the same groups or not, and 3) to balance learning activities between those that benefit face-to-face students more and those that benefit online students more. The third challenge is about the balance between not choosing learning activities that exclude online students - such as physical experiments - versus the potentially reduced learning outcome for face-to-face students when using online simulations instead of physical experiments. Careful consideration should be taken to at least achieve an overall balance between learning activities that benefit face-to-face students or online students more for the entire course.

\section{Active online learning of engineering}

Given the three dimensions of active online learning presented in Section 4, I propose in Figure 4 a guide to show how objectives formulated along the cognitive and social dimensions translate into activities and possible methods of evaluation and assessment - and also how digital resources can aid in the learning activities and evaluations. Note that this figure is based on the author's preferences and style of teaching, and different teachers may form different connections between objectives, activities, and evaluations. However, I believe that following the constructive alignment method of Biggs (1999) with objectives, activities, and assessments, the chart in Figure 4 can serve as a guide for designing an active online course that also takes into account the social dimension of online learning.

The Levels 1-4 learning objectives in Figure 4 are 


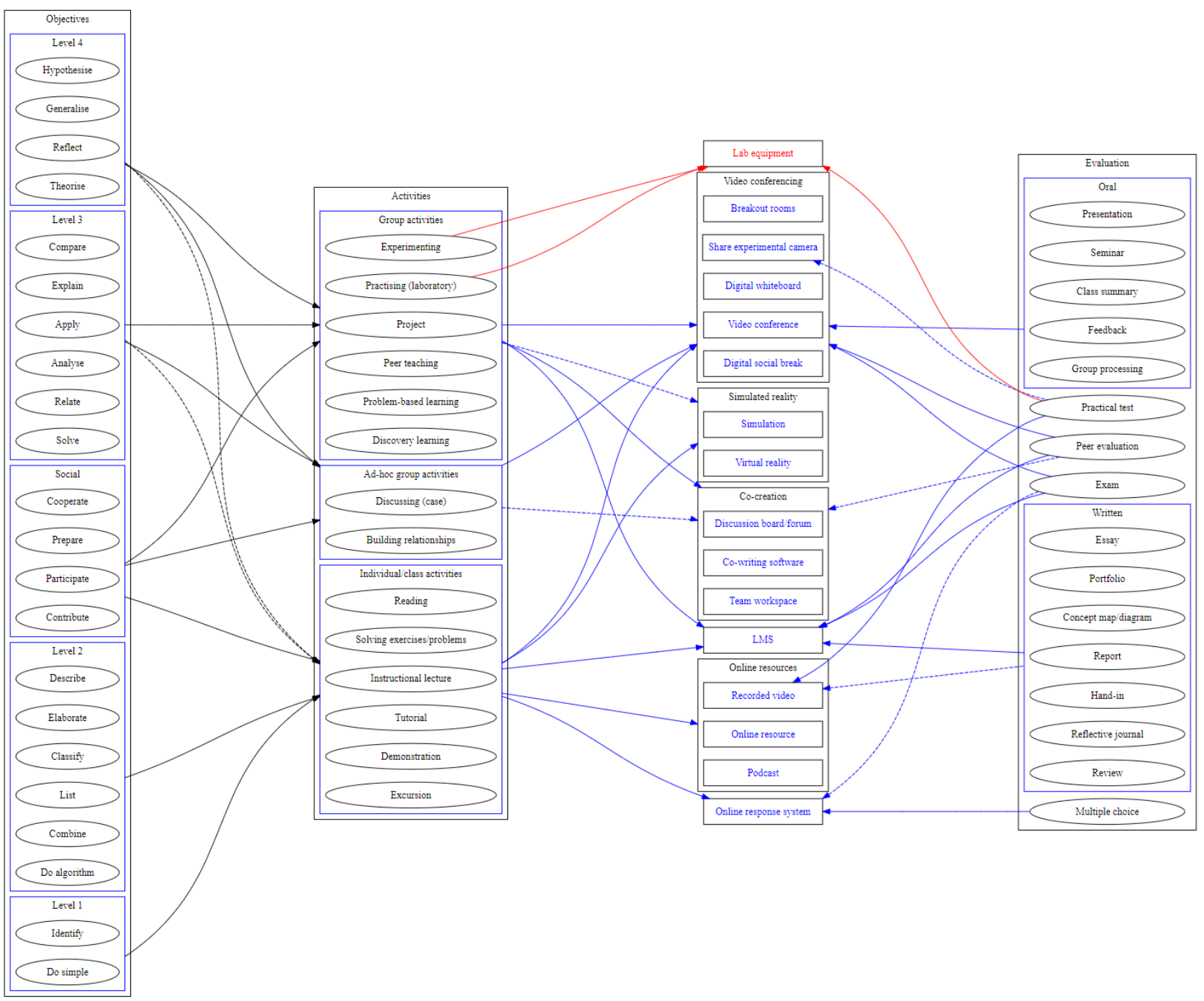

Figure 4: Graph of online learning objectives, learning activities, evaluation methods, and digital and physical resources. Arrows from activities to physical resources are shown in red, and to digital resources in blue. Solid lines indicate a strong link between concepts, dashed $(--)$ lines indicate a weaker link between concepts. Connections made to/from a cluster of concepts indicate that all concepts in the cluster are linked through the connection.

inspired from Biggs (1999), who formed the curriculum through clear objectives stating the level of understanding required for each objective, and used active verbs to specify the desired behaviour of students. In addition, building on the results on social interdependence by Johnson and Johnson (2009), I propose four social objectives on both an individual and a group level, and suggest that these must be met to some extent before group learning activities can succeed - and therefore also before higher-order learning objectives on Levels 3 and 4 can be met. It is hard to imagine a successful and effective group activity if students are not prepared or contributing to the group.
The learning activities in Figure 4 are inspired by the activities proposed by Lalley and Miller (2007), Biggs (1999), Johnson and Johnson (2009), Salmon (2002), and Hampel (2006). I have clustered the activities into individual/class activities - where there is little social interaction between students, and into group activities - with more social interaction between students. The groups can be informal ad hoc groups formed at the start of the activity for short discussions or for getting to know classmates, or more formal groups, as suggested in Johnson and Johnson (2009), forming project teams, lab partners, or learning groups, and whose membership lasts longer than 
for an ad hoc activity.

The evaluation methods and assessments in Figure 4 are inspired by different forms of evaluations proposed by Lalley and Miller (2007), Biggs (1999), and Johnson and Johnson (2009), and are only a selection from the large group of methods available for evaluating learning objectives and social objectives in a class. The selection is made based on what evaluation methods are most relevant for teaching engineering classes, and other fields may have different preferences for selecting evaluation methods.

In a purely online or a blended learning course, both learning activities and evaluation methods should take advantage of available digital resources. I propose a number of digital resources in Figure 4 to aid and inspire readers to find appropriate digital resources in their online teaching activities and evaluations. The list is far from exhaustive, but is based on currently available and mature technologies that teachers can apply to online courses without needing explicit programming skills or formal training to use the different technologies.

Note that the use of audiovisual material (see Lalley and Miller (2007)) in presentations, video conferences, etc., has become common today, and is implicit in the figure and therefore left out for clarity. Screen sharing in video conferences is supported by almost all video conferencing systems, and is not explicitly shown in the figure, but is included in the resource "video conference".

Figure 4 can be used as a guide to student-active online learning in the following way. First, clear objectives (both learning objectives and social objectives) should be stated for the course using descriptive verbs (either taken from the leftmost column in Figure 4 or using appropriate synonyms). Second, activities that support the selected objectives should be chosen from the second column - either from the individual/class cluster if objectives are on Levels 1 or 2, or combined with group activities if objectives are social or on Levels 3 or 4 . Third, digital (and physical) resources may now be chosen from column three to support those activities online. Fourth, the desired form(s) of evaluation should be chosen from the fourth column of Figure 4, and last, the digital resources that support the selected evaluation methods for the course should be chosen from the resource elements in the third column.

As an example, if the course objective is for students to be able to list facts or concepts, individual/class activities, such as reading or an instructional lecture, can be sufficient learning activities. The reading activity may be supported by additional online resources, and the instructional lecture may be supported by a video conferencing system sharing a presentation and a digital whiteboard for drawing/writing. The outcome of the activities can be evaluated using, e.g., a multiple-choice quiz conducted via an online response system.

Note that both direct instruction and asynchronous learning videos mainly encourage lower-level cognitive processes, and should be followed by one of the more student-active learning methods if we expect students to be able to attain high-level learning objectives. Thus, if the learning objective is for students to be able to identify, classify, or maybe compare some concepts, an asynchronous video lecture could be sufficient, but if the objective is to make students able to reflect or theorise about the methods, one of the student-active learning methods should be employed.

The list of digital resources does not mandate any particular software for the different online activities, but from the list, it is possible to extract some requirements for the set of digital resources that should be available to an online engineering class. First, it is important to have a suitable learning management system (LMS) to organise information provided to students, and to facilitate hand-ins, text-based discussions, and group management tasks. The organisation of information in the LMS is even more important in an online course than in a face-to-face course, and teachers should be very clear and explicit in providing directions and information on the LMS to avoid misunderstandings or missed information. One recommendation is that teachers should make an overall structure organising the LMS, and then explicitly explain this structure every time they refer to new assignments, new lecture material, or new information.

Second, it is important to have a good online video conferencing tool that allows real-time two-way communication between teacher and students, between students, and between groups of students. In practice, this requirement means that the online video conferencing tool must support the creation of breakout rooms (groups) of participants, and functionality for chats both within the full-class video conference and in the breakout rooms - for asking questions, commenting, and discussing. A particularly nice feature of a video conferencing tool, which simplifies discussion management for large student groups, is the possibility of raising a digital hand to signal that a participant wants to speak. The importance of proper audiovisual equipment and of agreeing on a set of digital class rules on muting, video on/off, private chats, etc., are also crucial factors for successful video conferences. Generally, students should be encouraged to turn on their video for online video conferences, but many students are hesitant to show their video, and clear expectations from the teacher on this subject should be expressed 
as early as possible in a course. The video conference system should support digital whiteboards (integrated through add-on devices or through online services), and preferably should connect a second camera for showing physical demonstrations and experiments (the demonstration can be shown using the primary web camera, but makes it more cumbersome). Online quiz support (student response systems) in the video conference system can also be beneficial, but there are plenty of dedicated softwares that provide this functionality, and it can also be integrated in the LMS.

Third, recorded video lectures and podcasts are asynchronous resources that can be made either through using dedicated software, or through using the recording functionalities of many video conferencing systems, and are a good alternative to synchronous online instructional lectures. They can also be useful for demonstrations and tutorials, and videos can sometimes be a sufficient substitute for real-life excursions.

Fourth, a digital team workspace, either in the LMS or using dedicated software (e.g., Slack, Microsoft Teams, etc.), can greatly support many group activities, and can also strengthen the social dimension of online learning by letting students dedicate some of the communication channels for personal and less formal communication.

Last, many digital tools may offer more than their traditional real-life counterparts do. Online resources can supplement textbooks and papers to inform students in their reading activities, and virtual reality can be useful for demonstrations, tutorials, and discovery learning. Online collaborative whiteboards (e.g., flinga.fi, padlet, etc.), where students can post ideas or questions or reflect on concepts in real time to support peer or whole-class discussions, have been shown to create an informal atmosphere that encourages students to ask more questions, and also to create a sense of social connectedness between students as reported in Ludvigsen et al. (2019). These collaborative whiteboards may be particularly important for larger groups, and especially if there are few social relations between students from before. Some services offer anonymity for participants, and this anonymity can encourage students who are hesitant to participate in larger groups to contribute.

A final note on digital resources is that it is quite possible to have digital coffee breaks as ad hoc activities to strengthen social relationships between students. While this digital social break is not necessarily the same type of digital resource as the others proposed in this paper, it is a quite useful resource for building social relationships among online students, and is therefore included in Figure 4 as a resource.

Note also that two learning activities commonly used in teaching engineering, practising (laboratory) and experimenting, are also linked to a physical resource in Figure 4 - the lab equipment. Although the learning activity of experimenting can be aided by simulations, in many engineering disciplines the activities of experimenting and practising on physical laboratory equipment are mandatory activities to achieve the skills needed to graduate. Recently, lab facilities are increasingly put online to provide online experimentation and laboratories for students, but these online laboratories are mostly for running closed process-models and machines with little interaction with the world outside the lab equipment. For experimenting and practising on real-life scenarios with environmental disturbances, etc., the availability of online laboratories is scarce. Thus, for the time being, I suggest that if someone is designing an online engineering course that emphasises the importance of students experimenting and practising on lab equipment or machines to learn a certain skill, the course should most likely be a blended course with some activities placed in physical laboratories. These lab activities are, however, also a good opportunity to build stronger social relationships between students.

In concluding this section on active online learning of engineering, it is important to note that students may not be familiar or may not intuitively understand every digital tool or resource they are exposed to in the course. A short tutorial on the important digital resources used in the course may be necessary for getting students started with new digital tools. Getting an overview of students' competencies in digital tools (and other prerequisites for the course) can be a good start to a course to make sure students are familiar with the tools, and this information can be gathered using anonymous student response systems at the start of the course.

\section{Active online learning in a mobile robotics course}

This section sums up the concepts discussed so far in an example to design an online course in mobile robotics. In addition to the objectives, activities, methods of evaluation, and available physical/digital resources that are used for designing the online course, the design process also takes into account the expected background knowledge of students, the acquired study skills of students, and the scientific content of the course.

The example course is a 4 ECTS module on mobile robotics as part of the 10 ECTS robotics course at Western Norway University of Applied Sciences. Par- 
ticipating students are in their third and final year of their BA studies, and belong to three different campuses of the university in three different cities. Students are expected to be familiar with the necessary mathematical background and concepts from control theory, but lack application-specific knowledge of robotics, and of how robots are traditionally modelled and controlled. Students participate mainly in three groups from classrooms at each campus equipped with basic audiovisual systems, but some students may also choose to join as individuals from home. Students at the same campus know each other from before, while students from different campuses do not. Students in previous years have been known to prepare little before lectures, but to participate to some extent in lectures through asking or answering questions. In previous years, the course has been taught using mostly teacher-active learning strategies, but also with some group work in the laboratory. The choice of video conferencing system is Zoom, and the mandatory LMS for the course is Canvas. The course is based on chapters $4-6$ in the textbook "Robotics, Vision and Control" (Corke, 2017).

Learning and social objectives have been formulated for the course using the active verbs of Figure 4 . The objectives for the course are that students should be able to

- explain and compare kinematic models of the different mobile robots in Corke (2017),

- theorise new kinematic models from drawings or descriptions

- solve kinematic control problems to steer the different types of mobile robots in Corke (2017) to a point, pose, or trajectory, and apply the control laws in simulations

- classify mobile robots into holonomic and nonholonomic systems, and explain these concepts

- compare and reflect on the best mobile robot navigation strategies from Corke (2017) in different situations

- apply the different navigation algorithms of Corke (2017) in simulations

- explain and compare the different localisation techniques for mobile robots in Corke (2017)

- explain the Kalman filter for inertial navigation

- explain simultaneous localization and mapping (SLAM)

- be prepared for and participate in learning activities
- cooperate with others on group assignments, and contribute to discussions and other students' learning

- reflect on the cooperation, and on possible improvements

There are four learning objectives on mobile robot models, two on mobile navigation, three on localisation and mapping, and three social objectives for learning. Most learning objectives are on Level 3 in Figure 4, but there are two Level-4 objectives, and one Level-2 objective. Based on the guide in Figure 4, I have selected a number of learning activities that support these objectives, and have selected a set of evaluation methods to evaluate learning progress towards the objectives. The selected learning activities are

- individual/class activities: reading, instructional lecture, solving exercises/problems, and demonstration

- group activities: peer teaching, practising (laboratory), discovery learning, and project

- ad hoc group activities: discussing (case), and building relationships

The evaluation methods used in the course are divided into oral methods: class summary, group processing, and feedback, and written methods: report, hand-in, and other methods: practical test, multiple choice quizzes, and an exam. The activities and evaluations are supported by the digital resources for a video conference using breakout rooms, a digital whiteboard, a shared experimental camera, and digital social breaks, and also by the LMS, an online response system, simulations, and by recorded videos and other online resources. The practising activity and practical test demands also the use of physical lab equipment.

The objectives, activities, evaluations, and resources for the course in mobile robotics are shown in Figure 5. Note again that the digital social break can hardly be defined as a digital tool in itself, but is an important (and often forgotten) mechanism for stimulating social relations between students.

From the objectives, activities, and evaluations, I can construct two plans for the course on mobile robotics. The overall course plan will address the listed objectives through learning activities, and will follow up with overall evaluations of the whole course. The lecture plan will address a typical lecture (typically 2-4 hours) on a specific subject in the course.

The course plan of when to teach what content follows closely the chronological order from the listing of the learning objectives earlier in this section, and is 


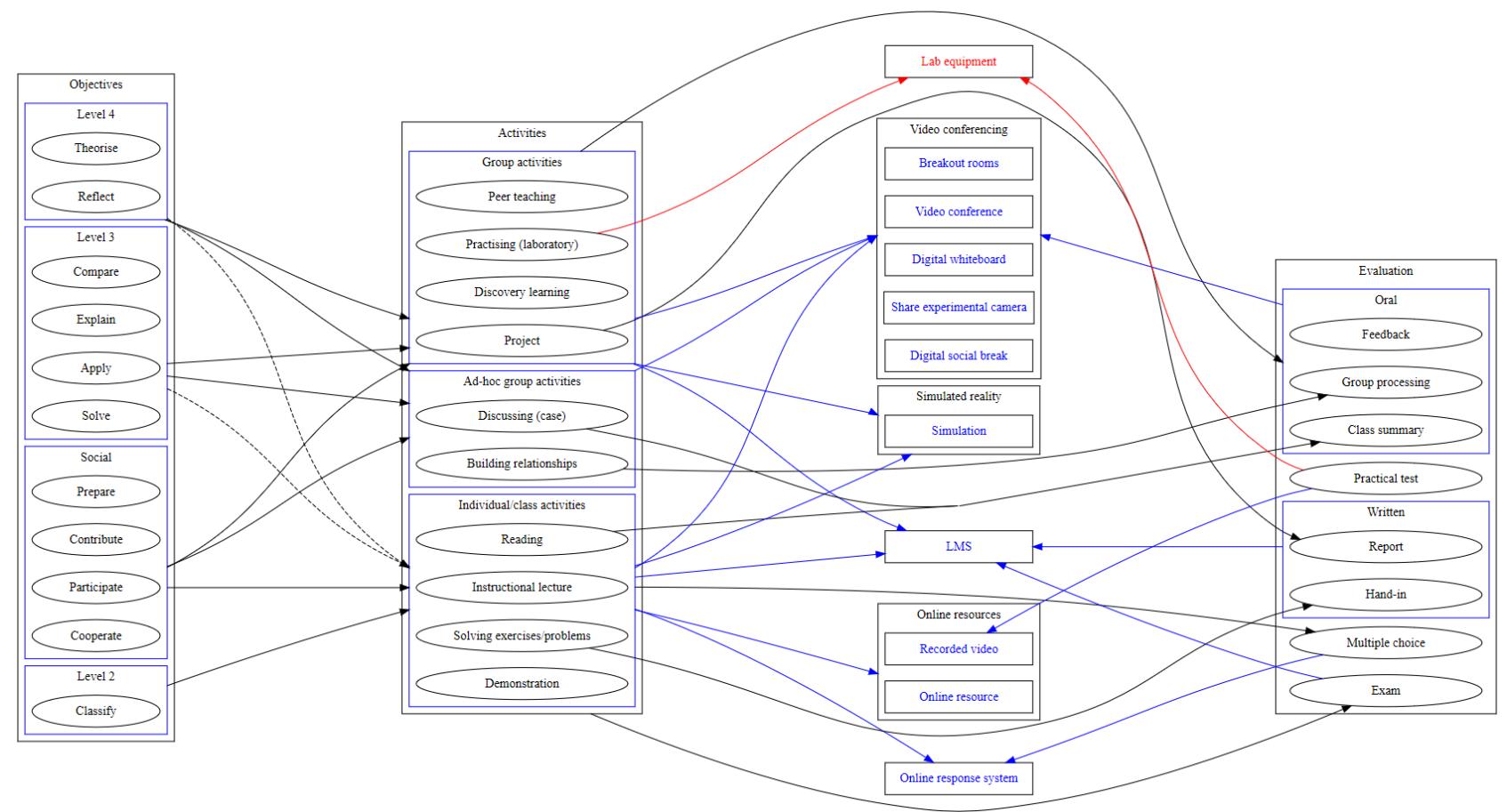

Figure 5: Graph of online learning objectives, learning activities, evaluation methods, and digital and physical resources for a course on mobile robotics.

not repeated here. The social objectives, however, will be addressed for every lecture, but more emphasis will be put on activities supporting the social objectives at the start of the course to create a learning environment that supports both class and group activities. The course plan will therefore adopt the five stages for active online learning from Salmon (2002) to support 1) access and motivation - welcoming students, 2) online socialisation - building relationships, 3) information exchange, 4) knowledge construction - collaborative interaction, and 5) development - reflection on the learning process. Since the course design process suggests that the course should be an online blended course with online learning supplemented with laboratory work on physical lab equipment, I have combined the stages of welcoming and socialisation with access to the physical lab equipment. Building on the findings of Lalley and Miller (2007), where students showed more retention when concepts where introduced in a practical laboratory context followed by a lecture than vice versa, the students will experiment and practise in the physical lab while also building social relations very early in the course plan. In the first lecture of the course, an anonymous survey using the online response system will be conducted to map the motivation of students for the course, the background knowledge and study skills of students, and also how familiar they are with the digital tools they will use. I will also ad- dress the overall expectations I have for the students concerning what learning objectives I expect students to attain in the course, what activities I expect them to take part in, and will in particular focus on the social objectives I expect them to contribute to. Digital class rules on always having the camera activated while participating in class will be established in this lecture, since this is an important aspect to promote the social dimension of the learning environment.

Based on the objectives, activities, and evaluations, and the suggested digital and physical resources, I can construct a lecture plan as illustrated in Table 1 that addresses both the abstraction of the learning objectives and the social objectives of the course. Note that in Table 1, the video conferencing system is assumed active for the entire online lecture, and this assumption is not always explicitly stated in the table. All activities are not necessarily evaluated immediately after an activity, but can also be evaluated in a general evaluation following a lecture or at fixed points during the semester, or as part of the exam.

In the lecture plan in Table 1, I expect students to read the textbook and use the available additional materials, such as online resources and asynchronous videos, to prepare for the lecture. This objective may be evaluated using multiple-choice quizzes embedded into the additional material, or by having multiple-choice quizzes available for students to help 
Table 1: Lecture plan for mobile robotics.

\begin{tabular}{|c|c|c|c|}
\hline Activity & Objective & Evaluation & Resource \\
\hline \multicolumn{4}{|l|}{ Before lecture: } \\
\hline Reading & Prepare & (Multiple choice) & $\begin{array}{l}\text { Online response system, online } \\
\text { resources; recorded videos }\end{array}$ \\
\hline \multicolumn{4}{|l|}{ First session: } \\
\hline Welcome & Cooperate, participate & None & Video conference \\
\hline $\begin{array}{l}\text { Explain objectives, ac- } \\
\text { tivities, and evaluation }\end{array}$ & Reflect & None & Video conference \\
\hline $\begin{array}{l}\text { Discussion on prepara- } \\
\text { tions, ad hoc groups }\end{array}$ & $\begin{array}{l}\text { Prepare, explain, reflect, } \\
\text { participate }\end{array}$ & Class summary & Breakout rooms \\
\hline Demonstration & $\begin{array}{l}\text { Explain, apply, compare, } \\
\text { (solve) }\end{array}$ & None & $\begin{array}{l}\text { Share experimental camera, } \\
\text { simulations }\end{array}$ \\
\hline Instructional lecture & $\begin{array}{l}\text { Classify, explain, compare, } \\
\text { solve, contribute }\end{array}$ & $\begin{array}{l}\text { (Multiple choice, } \\
\text { exam) }\end{array}$ & Digital whiteboard \\
\hline Case discussion & $\begin{array}{l}\text { Explain, reflect, compare, } \\
\text { solve }\end{array}$ & Class summary & $\begin{array}{l}\text { Breakout rooms, digital white- } \\
\text { board }\end{array}$ \\
\hline \multicolumn{4}{|c|}{ Scheduled break } \\
\hline \multicolumn{4}{|l|}{ Second session: } \\
\hline Instructional lecture & $\begin{array}{l}\text { Classify, explain, compare, } \\
\text { solve, contribute }\end{array}$ & None & Digital whiteboard \\
\hline Solve problems & Solve, apply & Hand-in & $\begin{array}{l}\text { Breakout rooms, digital white- } \\
\text { board, simulations }\end{array}$ \\
\hline Discussion on exercises & $\begin{array}{l}\text { Explain, reflect, compare, } \\
\text { solve }\end{array}$ & Class summary & $\begin{array}{l}\text { Breakout rooms, digital white- } \\
\text { board }\end{array}$ \\
\hline & \multicolumn{2}{|c|}{ Digital social break: } & \\
\hline Building relationships & Cooperate, contribute & Group processing & $\begin{array}{l}\text { Breakout rooms, Digital social } \\
\text { break }\end{array}$ \\
\hline \multicolumn{4}{|l|}{ Third session: } \\
\hline Instructional lecture & $\begin{array}{l}\text { Classify, explain, compare, } \\
\text { solve, contribute }\end{array}$ & $\begin{array}{l}\text { (Multiple choice, } \\
\text { exam) }\end{array}$ & Digital whiteboard \\
\hline Discovery learning & $\begin{array}{l}\text { Theorise, cooperate, apply, } \\
\text { contribute }\end{array}$ & $\begin{array}{l}\text { Class summary, } \\
\text { group processing }\end{array}$ & $\begin{array}{l}\text { Breakout rooms, digital white- } \\
\text { board, simulations }\end{array}$ \\
\hline $\begin{array}{l}\text { Discussion; class and } \\
\text { groups }\end{array}$ & Reflect & Group processing & $\begin{array}{l}\text { Video conference, breakout } \\
\text { rooms }\end{array}$ \\
\hline
\end{tabular}

\section{Scheduled break}

Fourth session:

Practising (laboratory) $\quad \begin{aligned} & \text { Apply, explain, solve, co- } \\ & \text { operate, contribute, reflect }\end{aligned} \begin{aligned} & \text { Practical feedback } \\ & \text { feest, Lab equipment, simulations }\end{aligned}$

Video conferencing is always used for the lecture for linking classrooms and participants together with video, for "raise hand" functionalities, and to enable ad hoc breakout rooms to be formed across campuses.

self-evaluate their preparations before each lecture.

The first session of the lecture starts with a welcoming activity to make sure students are seen and recognised as important participants in the class. The second activity clearly explains the learning objectives and activities in the lecture, and how the objectives will be evaluated. Both these first two activities of the session are done as whole-class activities using the 
online video conference system.

Following the reflection on objectives and activities, the students are divided into small ad hoc groups in breakout rooms across campuses of two to three students to discuss their preparation for this lecture, and to prepare at least one question about the prepared material for the class summary. In addition to targeting the learning objectives, this group discussion also aims at creating social relations between students at different campuses.

The course in mobile robotics contains many practical examples through either simulations or practical experiments, and the demonstration activity will demonstrate simulations or practical experiments (inspired by Lalley and Miller (2007)) of the concepts before introducing the theoretical basis for them in the next activity. The following short instructional lecture activity builds on the prepared text and additional material, and highlights the most important concepts from this material. The session is concluded by a case discussion on the lectured material in small ad hoc groups (2-3 students, mixed campus) with a class summary afterwards.

The second session in the lecture starts with an instructional lecture activity on how to apply the concepts in practise, and is followed by an activity of students solving exercises or problems in small breakout rooms - and helping each other. The session is concluded by a class summary reflection on the problems, and a more thorough explanation of common difficulties.

The second break is a digital social break where students are divided into three- or four-person ad hoc groups across campuses to discuss off-topic issues, and where a few groups are expected to report back to the class on their topic of discussion to ensure participation in the group discussions.

The third session starts with an instructional lecture on a topic that students have not yet prepared for, but will prepare for before the next lecture. This activity is followed by a discovery-learning session in learning groups, where a variant of the discovery-learning activity described in Lalley and Miller (2007) is employed, and where students are given small problems designed to discover principles or relationships using online simulations (rather than through physical experiments). This discovery-learning activity is evaluated using a group reflection process in the learning groups, and also through a short class summary after the activity.

The last session of the lecture involves practising the knowledge from the preparations, instructional lectures, demonstrations, and discussions in a laboratory exercise. Parts of the lab activity may be done using online simulations or online experimental resources, but there will also be practical experiments that must be done on physical lab equipment in the laboratory on the different campuses.

In the lectures, I propose to address the blended group learning challenges of students participating in groups on different campuses or as individuals from home by allowing students to group physically in classrooms if desired, but all students participating in the course should also be connected to the video conferencing tool with proper audiovisual equipment (headset with microphone, web camera). This connection allows students to use the raise-hand functionality of the video conferencing tool, and allows the teacher to give attention to all participants on equal terms, to form ad hoc groups across campuses using breakout rooms, and to switch easily between face-to-face discussions and digital discussions between students. This connection also ensures that all participants - face-to-face and online - can see and hear everyone contributing with questions about or inputs to the class learning activities. The online collaborative whiteboard flinga.fi with anonymous participation will be employed to lower the threshold of asking questions or commenting on the material during sessions.

\section{Conclusions}

This paper proposes a guide to designing student-active online courses for engineering. The proposed guide takes into account the social processes between students as a prerequisite for successful group activities, and also suggests digital resources to aid both in learning activities and in the evaluation of progress towards learning objectives and social objectives. The guide is applied to redesign a traditional course in mobile robotics into an online course to exemplify the usefulness of the guide. In the future, the effect of the redesign on the learning outcomes from the course will be investigated to provide additional insight into how different online learning activities can be supported by digital resources to achieve the desired learning and social objectives of a student-active online course in engineering.

\section{Acknowledgements and Author's contribution}

This work was partially funded by the Research Council of Norway through grant number 280771. E. Kyrkjebø wrote the paper, and thanks everyone who has made useful comments about the manuscript. The author is also grateful for the opportunity to learn GraphViz for making Figures 4 and 5. 


\section{References}

Biggs, J. What the student does: teaching for enhanced learning. Higher Education Research \& Development, 1999. 18(1):57-75. doi:10.1080/0729436990180105.

Corke, P. Robotics, Vision and Control: Fundamental Algorithms in Matlab. Springer International Publishing, 2 edition, 2017. doi:10.1007/978-3-31954413-7.

Dale, E. Audio-visual methods in teaching. The Dryden Press, 2 edition, 1954.

Freeman, S., Eddy, S. L., McDonough, M., Smith, M. K., Okoroafor, N., Jordt, H., and Wenderoth, M. P. Active learning increases student performance in science, engineering, and mathematics. Proceedings of the National Academy of Sciences, 2014. 111(23):8410-8415. doi:10.1073/pnas.1319030111.

Goodhew, P. Teaching Engineering. UKCME, 2014.

Goodyear, P. Teaching Online, pages 79-101. Springer Netherlands, Dordrecht, 2002. doi:10.1007/978-94010-0593-7_5.

Hampel, R. Rethinking task design for the digital age: A framework for language teaching and learning in a synchronous online environment. ReCALL, 2006. 18(1):105-121. doi:10.1017/S0958344006000711.

Hannay, M. and Newvine, T. Perceptions of distance learning: A comparison of online and traditional learning. Journal of Online Learning and Teaching, 2006. 2(1):1-11.

Johnson, D. W. and Johnson, R. T. An educational psychology success story: Social interdependence theory and cooperative learning. Educational Researcher, 2009. 38(5):365-379. doi:10.3102/0013189x09339057.

Keengwe, J. and Kidd, T. T. Towards best practices in online learning and teaching in higher education. MERLOT Journal of Online Learning and Teaching, 2010. 6(2):533-541.
Lalley, J. P. and Miller, R. H. The learning pyramid: Does it point teachers in the right direction? $E d u$ cation, 2007. 128(1):64 - 79 .

Letrud, K. A rebuttal of ntl institute's learning pyramid. Education, 2012. 133(1).

Ludvigsen, K., Ness, I. J., and Timmis, S. Writing on the wall: How the use of technology can open dialogical spaces in lectures. Thinking Skills and Creativity, 2019. 34:100559. doi:10.1016/j.tsc.2019.02.007.

Marton, F. and Säljö, R. On qualitative differences in learning: I - outcome and process. British Journal of Educational Psychology, 1976. 46(1):4-11. doi:10.1111/j.2044-8279.1976.tb02980.x.

National Academy of Engineering. Changing the Conversation: Messages for Improving Public Understanding of Engineering. The National Academies Press, Washington, DC, 2008. doi:10.17226/12187.

Olapiriyakul, K. and Scher, J. M. A guide to establishing hybrid learning courses: Employing information technology to create a new learning experience, and a case study. The Internet and Higher Education, 2006. 9(4):287 - 301. doi:https://doi.org/10.1016/j.iheduc.2006.08.001.

Pawley, A. L. Universalized narratives: Patterns in how faculty members define "engineering". Journal of Engineering Education, 2009. 98(4):309-319. doi:10.1002/j.2168-9830.2009.tb01029.x.

Pigford, V. D. A comparison of an individual laboratory method with a group teacher -demonstration method in teaching measurement and estimation in metric units to preservice elementary teachers. Technical report, Florida State University, ERIC Document Service (ED108928), 1974.

Salmon, G. E-tivities: The Key to Active Online Learning. Kogan Page, London, 2002.

Wieman, C. E. Large-scale comparison of science teaching methods sends clear message. Proceedings of the National Academy of Sciences, 2014. 111(23):8319-8320. doi:10.1073/pnas.1407304111. 